\title{
An Investigation into the Precipitation of Asphaltene from Maltenes Using Binary Mixtures of N-Paraffin
}

\author{
Utin Mfon Clement, Ofodile S .E, Osuji L. C \\ Department of Pure and Industrial Chemistry, \\ University of Port Harcourt, Choba Port Harcourt, Rivers State, Nigeria
}

\begin{abstract}
This work investigates the precipitation of asphaltene from maltenes using single and binary mixtures of $n$-alkanes. The maltenes was obtained by the precipitation from crude oil using $n$-alkanes $\left(n C_{5^{-}}\right.$ $\left.n C_{7}\right)$. These were deasphalted with a lower carbon number solvent $\left(n C_{5}\right)$. The result shows the co-precipitation of the asphaltene are saturates, aromatics and resins. The result obtained generally shows that the asphaltene precipitation from maltenes increased as the n-alkane carbon number of the original precipitating solvent increased.
\end{abstract}

Keywords: Crude oil, n-alkane( n-paraffin), asphaltene, maltene, precipitation, carbon number range.

\section{INTRODUCTION}

During production, transportation and processing, petroleum fluids may go through a number of phase changes which include evaporation (separation of gases from liquid streams), retrograde condensation (separation of liquid from gas stream) and solid formation and deposition (separation of crystalline solids, colloids and aggregates from liquid or vapour streams) which may lead to precipitation and/or deposition of diamonoids, wax and asphaltene (12).

Asphaltenes are defined as the fraction separated from crude oil or petroleum products upon addition of hydro-carbon solvents such as n-heptane (14). The formation and deposition of asphaltene-rich, solidlike material during oil recovery operations have been well documented in the literature $(7,9,17)$. Asphaltenes are often considered troublemakers because of their tendency to flocculation (2).

Asphaltene precipitation and deposition can occur during production of reservoir fluid, transportation of produced fluid and processing of the fluid in downstream operations. Conditions where asphaltene precipitation can occur during conventional crude oil production include normal pressure depletion, acid stimulation, gas-life operations and miscible flooding for enhanced oil recovery. In some field cases, asphaltenes and waxes co-precipitate. During heavy oil operations, the dilution of heavy oil with paraffinic solvent or lighter oils to reduce its viscosity can cause asphaltene precipitation in pipelines, tubular and surface facilities. Asphaltenes also precipitates during treatment in oil sand processing and vapour extraction process for heavy oil recovery $(4,15)$.

Precipitation of dispersed asphaltene particles is a precondition for deposition in process equipment. Deposition of asphaltene in oil wells, pumps, flowlines, pipelines and production facilities can reduce well productivity, damage pumps, restrict or plug flow line and pipelines and foul production handling facilities (15). Precipitated asphaltene may also build-up in the near well-bore, reservoir rock and clog the porous matrix of the reservoir during drilling and chemical treatment $(8,11)$. Apart from causing the reservoir formation damage, asphaltene deposits could also result in reversal of the rock wettability which leads to a lower recovery factor (22).

Field problems from plugging of well bone, tubing and surface facilities due to asphaltenes have been reported from a large number of production fields with both light and heavy oil production. Some examples of these cases are in the Algeria (6), USA (9), North Sea (16), Vanezuela (3) and Kuwait (1).

In addition to the problems related to flow assurance and reservoir impairment, asphaltenes are also known to contribute to the formation of stable emulsions in process facilities (10) and act as coke precursors and catalyst poisons (5). Although operators try to avoid the conditions where asphaltene precipitation occurs, in some cases, precipitation and the potential accumulation of asphaltene 
deposits is inevitable. Therefore, operators must rely on chemical and mechanical remediation methods to mitigate deposition. These methods are expensive and are often only partially effective. Consequently, understanding the mechanisms of asphaltene precipitation and deposition is vital to the application of these remedial mitigation methods (15)

The mechanism of deposition of heavy organics from crude oil in the field can better be understood by precipitations of heavy organics from crude oil in the laboratory using binary mixtures of $n$-alkane solvents than single solvents. The trends of precipitation in single n-alkane solvent demonstrate a corresponding decrease in the quantity of precipitate as the carbon number of n-alkane organic solvents increases. Precipitation with binary mixtures n-alkane shows a three- stage phase transition: solid-liquid, liquid-solid and solid-liquid, as the volume ratios of the precipitants vary (18).

The aim of this research is to obtain the quantity of $\mathrm{nc}_{5}$ (pentane) insoluble of heavy organics in the filtrate.

\section{Material AND Method}

\section{Apparatus/ Equipment:}

Filtration System, Hot Plate, Distillation System, Thermometer, Desiccators, membrane filter.

Materials: Crude oil, Pentane, Hexane, Heptane

\section{Method}

The crude oil used for this research was obtained from NNPC research and development centre, Port Harcourt.

The reduced crude oil residue was obtained by removing the distillates at $260^{\circ} \mathrm{C}$ using atmospheric distillation at room pressure. Precipitation of heavy organics was carried out using both the undiluted solvent and binary mixture of the lower n-alkane solvents various ratio.

Thirty millimeters (30 mls) of each of the solvents (pentane, hexane and heptane) and 30mls of each binary mixtures (i.e $\mathrm{nC}_{5}: \mathrm{nC}_{6}, \mathrm{nC}_{5}: \mathrm{nC}_{7}$ and $\mathrm{nC}_{6}: \mathrm{nC}_{7}$ ) were added to $1 \mathrm{~g}$ of the reduced oil in appropriate flask. The mixtures were shaken for 30mins using mechanical shaker and kept for $48 \mathrm{hrs}$ before filtration. Each of the solutions was filtered using the filtration system with $0.45 \mathrm{~mm}$ membrane filter which was connected to vacuum pump to separate the solid precipitate from the filtrate. The solid precipitate was dried in an oven, weighed and kept in a desiccator. Each of the filtrates obtained from precipitation with both single and binary mixture of varying ratios were kept in a fume cupboard for complete evaporation and $15 \mathrm{ml}$ of pentane was added to each of the filtrate in their appropriate flask shaken for 30mins, kept for $48 \mathrm{hrs}$ and filtered using the vacuum pump system. The solid precipitate was dried in an oven, weighed and kept in a desiccator. The solid precipitate obtained was quantified on weight basis (scheme 1).

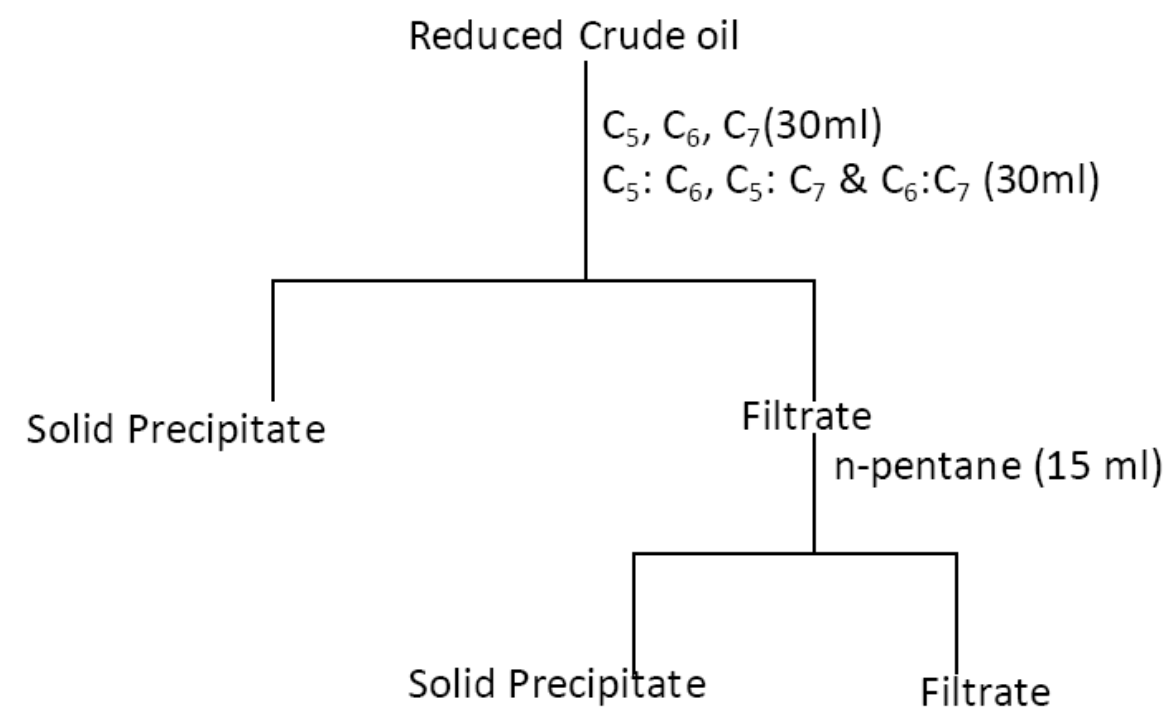

Scheme1. A Schematic Presentation of the heavy organics precipitation from filtrates (maltenes) obtained after precipitation from Nigeria Crude Oil Sample 


\section{RESUlTS AND DISCUSSION}

Table1. Weight of heavy organic precipitation

Mixtures at $30 \mathrm{ml} / \mathrm{g}$ of crude oil for HO precipitate and $15 \mathrm{ml} / \mathrm{g}$ for HO (ASPHALTENE) precipitate (filtrate)

\begin{tabular}{|c|c|c|c|c|c|c|}
\hline \multicolumn{7}{|c|}{ PRECIPITANT } \\
\hline $\begin{array}{c}\text { Solv } \\
\text { ent } \\
\text { Rati } \\
\text { o }\end{array}$ & $\begin{array}{c}\text { Wt of Ho } \\
\text { precipitate(g) } \\
\text { C }_{5} \text { \& }_{6} \\
\text { (FILTRATE) }\end{array}$ & $\begin{array}{c}\text { Wt OF Ho } \\
\text { (g) } \mathrm{C}_{5} \text { \& } \\
\text { C }_{6}(\text { CRUDE } \\
\text { OIL })\end{array}$ & $\begin{array}{c}\text { Wt of HO } \\
\text { PRECIPITATE } \\
\text { (g) } \text { C }_{5} \& \\
\text { C }_{7} \text { (Filtrate) }\end{array}$ & \begin{tabular}{|c|} 
Wt of HO \\
PRECIPITATE \\
(g) C $_{5} \&$ \\
C $_{7}($ CRUDE OIL $)$
\end{tabular} & $\begin{array}{c}\text { Wt of HO } \\
\text { PRECIPITATE } \\
\text { (g) } \mathrm{C}_{6} \& \mathrm{C}_{7} \\
\text { (filtrate) }\end{array}$ & $\begin{array}{c}\text { Wt of HO } \\
\text { PRECIPITATE } \\
\text { (g) } \text { C }_{6} \& \\
\text { C }_{7}(\text { CRUDE OIL })\end{array}$ \\
\hline $0: 1$ & 0.0435 & 0.0118 & 0.0698 & 0.004 & 0.0698 & 0.004 \\
\hline $1: 0$ & 0.008 & 0.0281 & 0.008 & 0.0281 & 0.0435 & 0.0118 \\
\hline $1: 1$ & 0.0131 & 0.0249 & 0.0127 & 0.0158 & 0.0451 & 0.0085 \\
\hline $1: 2$ & 0.021 & 0.0212 & 0.034 & 0.0132 & 0.05 & 0.0048 \\
\hline $2: 1$ & 0.0172 & 0.0242 & 0.0215 & 0.0151 & 0.047 & 0.0078 \\
\hline $1: 3$ & 0.0232 & 0.0234 & 0.038 & 0.0149 & 0.0562 & 0.0053 \\
\hline $3: 1$ & 0.012 & 0.0263 & 0.0134 & 0.0163 & 0.046 & 0.0099 \\
\hline
\end{tabular}

The result from the single solvent and binary mixture precipitants in fig 1,2,3 and table 1 of the precipitate shows that the lower the carbon number used for precipitation, the higher the precipitates and it was in lined with reported work done by (18). According to (19), the binary system of solvents leads to phase changes of heavy organics as the ratios of the n-alkane solvents vary. The maxima was observed at $1: 1(\mathrm{v} / \mathrm{v})$ ratio of solvent and the maxima were observed at solvent ratios of 1:2 and $2: 1(\mathrm{v} / \mathrm{v})$ binary mixtures. The binary system of the solvent lead to phase changes of the heavy organics as the volume ratios of the n-alkane solvents vary. This gives rise to a curve demonstrating the precipitation and deposition phenomena similar to those which occur in the field and the reported work of the binary mixtures shows the same trend in this research as shown in fig 1,2 and 3 that the lower the n-alkane solvent used for the mixture the higher the precipitate and verse versa.

From the filtrate, result obtained shows that the single $\mathrm{nC}_{7}$ (fig 6) precipitate has the highest amount of precipitate followed by the $\mathrm{nC}_{6}$ (fig 4) and finally the $\mathrm{nC}_{5}$ (fig 5). For the binary mixture of the various ratios the binary mixture that has the lower carbon number shows lower amount of precipitate while the one with the higher carbon number shows largest amount of precipitate in the filtrate as shown in table 1, figure 4,5 and 6. This shows a reverse observation to previous report by (20) which shows that the fraction of heavy organics insoluble in $n$-pentane is larger than that insoluble in $n$ heptane and contained wider range of molecules, including the fraction of n-pentane insoluble that was soluble in n-heptane (13). This research work has proven the point that most of the fractions of the heavy organics insoluble in n-pentane have been precipitate out in the initial precipitation process and that of $\mathrm{n}$-heptane which was lesser in the initial precipitation, with the deasphalted with n-pentane (precipitation) precipitate the entire amount including the fraction left in the n-pentane soluble which makes the $\mathrm{nC}_{7}$ highest in figure 5 of $0: 1(\mathrm{v} / \mathrm{v})$ ratio followed by $\mathrm{nC}_{6}$ (figure 6 ) and finally $\mathrm{nC}_{5}$ (figure 4 ) for the single solvent . This same trend was equally shown in the binary mixtures as shown in figure 4, 5 and 6 . The physical properties of asphaltenes are sensitive to the extraction method and / or solvents used for separation since the amount and exact chemical composition of extracted asphaltenes will vary with the different procedures. Moreover, asphaltenes precipitated using nheptane are more aromatic compared to asphaltenes precipitated using n-pentane and the hydrogen/carbon $(\mathrm{H} / \mathrm{C})$ ratio of asphaltenes precipitated using $n$-heptane is lower than the asphaltene precipitated using n-pentane defining ashaltene operationally rather than by their chemistry (15). It has been reported that ashaltene precipitation generally increases as n-paraffin as the n-paraffin carbon number increases. Asphaltene precipitation may reach a maximum of of nc9 or nc10 paradoxically, it can have high precipitation with smaller volume of n-hexadecane than with npentane, even though large volumes of n-hexadecane precipitate much less (and more aromatic) asphaltenes than large volumes of of n-pentane (21). According to (4), it was observed that above a ratio of $10 \mathrm{ml} / \mathrm{g}$ of oil, the precipitation is completed and also a decrease in the amount precipitated at very high dilution ratio was observed which can be attributed in part to partial redissolution of asphaltenes in the solvent. 


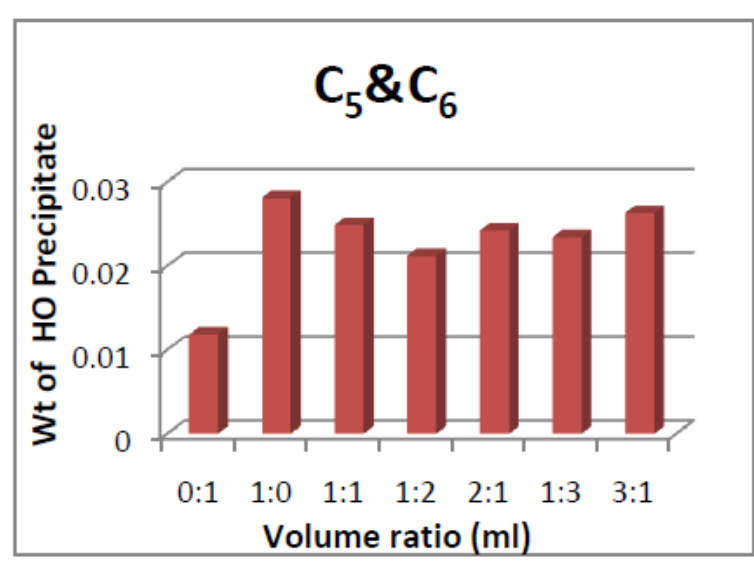

Fig1. Weight of Heavy Organics from Crude $\operatorname{Oil}\left(C_{5}: C_{6}\right)$

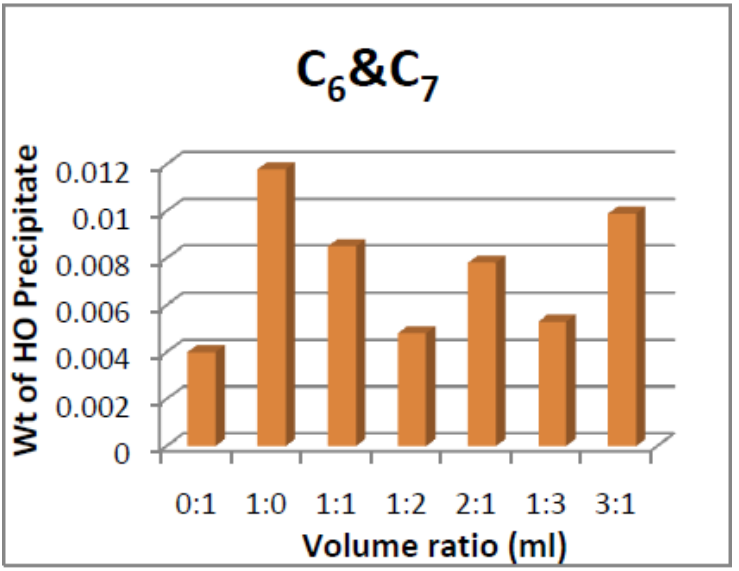

Fig3. Weight of Heavy Organic from Crude Oil $\left(C_{6}: C_{7}\right)$

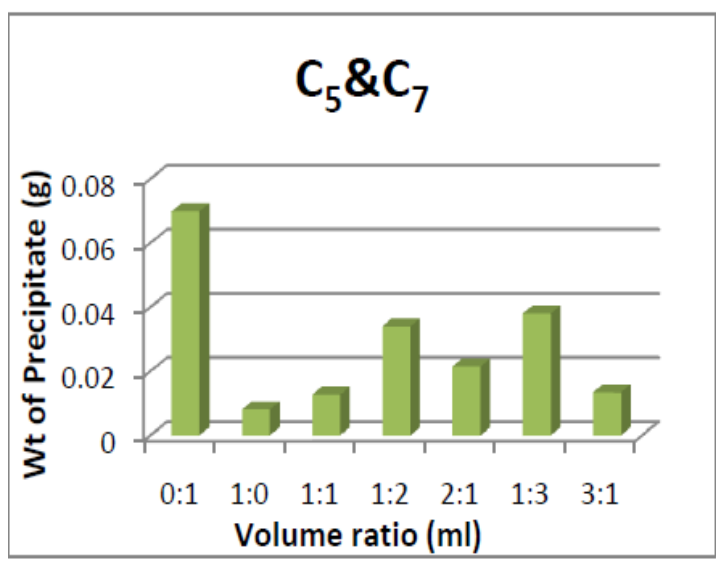

Fig5. Weight of Precipitate(Asphaltene) from Maltene (Filtrate) $C_{5}: C_{7}$

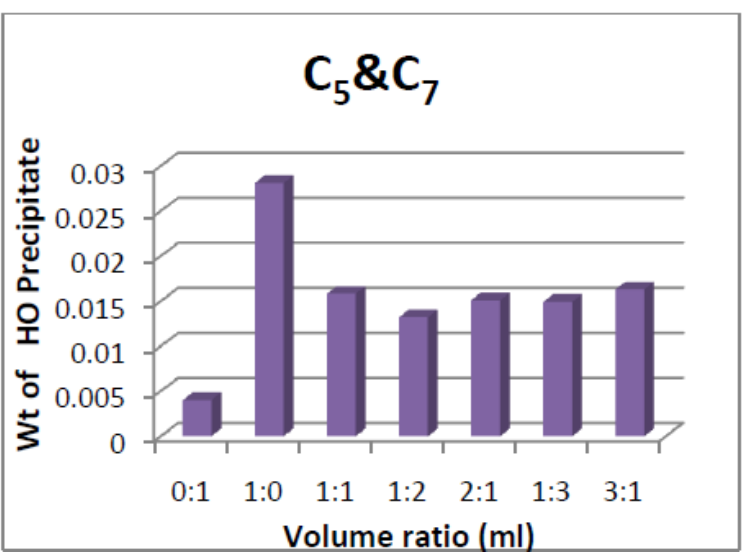

Fig2. Weight of Heavy Organic from Crude Oil $\left(C_{5}: C_{7}\right)$

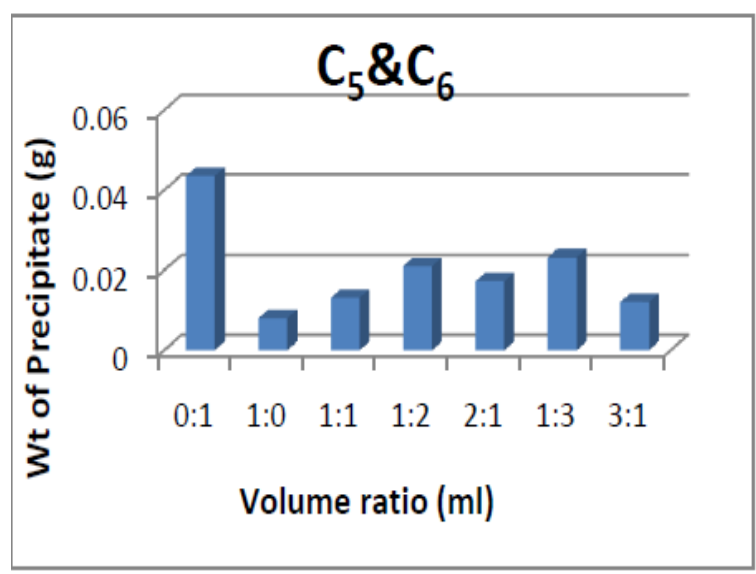

Fig4. Weight of Precipitate (Asphaltene) from Maltene (Filtrate) $C_{5}: C_{6}$

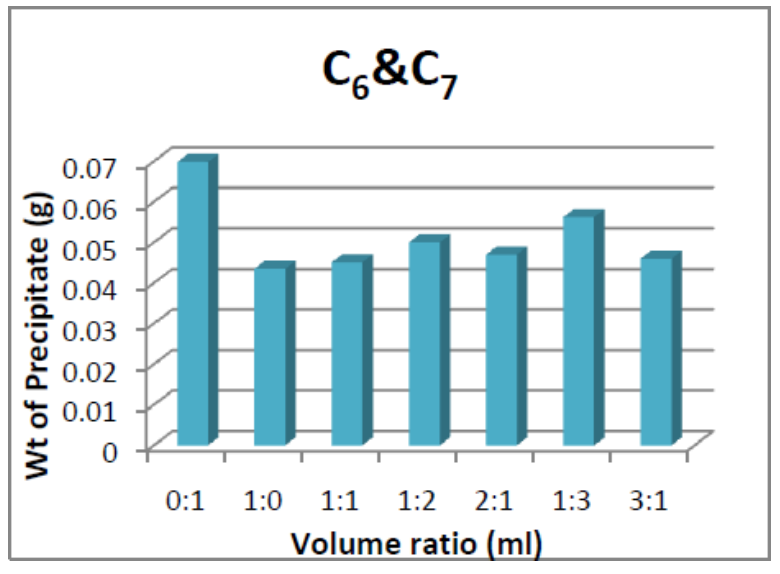

Fig6. Weight of Precipitate(Asphaltene) from Maltene (Filtrate) $C_{6}: C_{7}$

\section{Conclusion}

The research shows that a reasonable amount of asphaltic material in the maltene which prove the existence of co-precipitation. From table 1,it is observed that the $\mathrm{C}_{5}: \mathrm{C}_{6}$ and $\mathrm{C}_{5}: \mathrm{C}_{7}$ shows large amount of precipitate in the solid precipitate compare to the filtrate (maltene) while the $\mathrm{C}_{6}: \mathrm{C}_{7}$ precipitants of both single and binary mixture of maltene (filtrate)shows a large amount of precipitants compared to the solid precipitate because of the lower carbon solvent that was used to deasphaltene the maltene. It is observed that the amount of precipitating solvent in fig 1,2,3 that had high precipitate shows a smaller amount of precipitate in figure 4,5 and 6 and the ones with lower amount of the precipitates in figure 1,2 and 3 shows higher precipitates in figure 4,5 and 6 which is due to the lower carbon number solvent $\left(\mathrm{nC}_{5}\right)$ used for deasphalting process. 
The reported work by (20) shows that when n-pentane is used high-molecular weight paraffin coprecipitate with the asphaltene and resin with different types of asphaltenes which exhibit very different Molecular Weight distribution. The Molecular Weight distributions will depend on the level of interactions among asphaltenes, resin and co-precipitated high Molecular Weight paraffin.

\section{REFERENCES}

[1] Alkafeef, S.F., Al-Medhadi, F., Al-Shammari, A D. A simplified method to predict and prevent asphaltene deposition in oil well tubings: field case, SPE Production and facilities 126-132 (2005).

[2] Arnaud C. H .Digging into Asphaltenes Volume 87 Issue 38/pp. 12-17, Chemical \&Engineering News CASC \&ENACS Publications (2009).

[3] Cassani, F., Ortega, P., Davila, A., RODRIGUEZ, w., Lagoven, S.A., Seranno, J.,. Evaluation of foam inhibitors at the jusepin oil/gas separation plant, EL Furrial Field, Eastern Venezuela, Paper SPE 23681, Second latin American petroleum Engineering Conference, II LAPEC, Caracus, Venezuela (1992).

[4] Eduardo B.G. \& Calos L.G Alejandro G.V, Jianzhong W. Asphaltene precipitate in crude oils. Theory and experiments. Al CHE journal (2004).

[5] Gray, M. R., . Upgraping petroleum residues and heavy oils, Marcel Decker Inc., New York (1994).

[6] Haskett, C. E., Tartera, M.,. Practical solution to problem of asphaltenes deposits- Hassi Messaoud field, Algeria, J. Pet. Technol., 17(4), 387-391 (1965).

[7] Islam,M.R. Role of Asphaltenes on oil recopvery and mathematical modeling asphaltenea and asphalts, vol. 1,T.F. Yen and G. Chilingarian,eds, Elservier Science, Amsterdam, The Ntherlands, p 249 (1994).

[8] Leonataris, K. J., Amaefule, J. O., Charles R. E., . 'A systematic approach for the prevention of formation caused by asphaltene precipitation", SPE Production and Facilities (1994)

[9] Leontaritis, K.J., Mansoori, G. A. Aaphaltene deposition: a survey of field experiences and research approaches, J. Pet. Sci. Eng.,1(3), 229-239 (1998).

[10] Lindemuth, P. M., Lessard, R.B., Lozynski, M., Kremer, M. Improve desalter operations, Hydrocarbon Processing, 67-70 (2001).

[11] Luo, P., Wang, X., GUu, y., Zhang, H., Moghadam, S., Asphaltene precipitation and its effects on the vapour extraction (VAPEX) heavy oil recovery process, paper SPE/PS/CHOA 117527, SPE International Thermal Operations and Heavy Oil Symposium, Calgary, Alberta, 20-23 (2008).

[12] Mansoori Ali G. Phase behaviour in petroleum fluids: A detailed description and illusion account with emphasis on heavy organics (2008).

[13] Okoye I.P., Ofodile, S. E \& Chukwu, O.C. The effect of different solvent polarity on the precipitation of heavy organics from a crude oil deposit in the higher Delta (2011).

[14] Speight J. G. The chemistry \& technology of petroleum, Marcel Dekker, New York (1999).

[15] Tharanivasan A. K. . Aspahaltene Precipitation from Crude Oil Blends, Conventional Oils and Oils with Emulisified Water.2012

[16] Thawer. R., Nicoll, D.C .A., Dick,G., . Asphaltene deposition in production facilities. SPE Production Engineering (1990).

[17] Tutle, R.N . Hugh-Pour Point and Asphaltic Crude Oils and Condensates. J. petrol. Technol, 21,1192 (1983).

[18] Udourioh G.; Ibezim-Ezeani M.; and Ofodile S. Comparative Investigation Of Heavy Organics Precipitation From Crude Oil Using Binary Mixtures And Single N-alkane Organic Solvents. Journal of Petroleum and Gas Exploration Research .4 (4) 53-59 (2014)

[19] Udourioh G.; Ibezim-Ezeani M.; Millicent, U and Ofodile S. The effect of compositional changes of binary mixtures of n-alkane solvents on the precipitation of heavy organics from a solution of crude oil residue (2015). 
[20] Vazquez D and Mansoori G.A. Identification and Measurement of Petroleum Precipitates. Journal of Petroleum Science and Engineering. 26, 49-55 (2000).

[21] Wiehe I.; Yarranton H.; Akbarzadeh K.; Rahimi P. and Teclemariam A. The Parodox of Asphaltene Precipitation with Normal Paraffins. Energy and Fuel. 19(4), 1261-1267 (2005).

[22] Yan, J., Plancher, H.,. Wettability changes induced by adsorption of asphaltene, SPE Production and Facilities, 12(4), 239-266 (1997). 